\title{
Analysis of Cost Estimation Level from BIM Model and Development of QDB based Integrated Cost Management Model
}

\author{
Seokheon Yun* \\ Professor, Architectural Engineering Department, GyeongSang National University, JinjuSi \\ GyeongSangNamdo, 52828, Korea. \\ *Corresponding author. Tel: +82-10-8860-5626 ; Email address: gfyun @ gnu.ac.kr
}

Article History:Received:11 november 2020; Accepted: 27 December 2020; Published online: 05 April 2021

\begin{abstract}
A change in the traditional construction cost management system is necessary for systematic construction cost management through BIM, but it has yet to present practical improvements. In this study, we would like to present a framework for information structure for Building Information Modeling(BIM)-based construction cost management. In order to analyze the differences between the traditional construction cost management system and the BIM-based construction cost management system, the level of development (LOD) was used to analyze how much existing Bill of Quantity(BoQ) can be satisfied through the BIM model. To this end, the level of availability of information in the BIM model was analyzed for the traditional BoQ of the construction work. Based on LOD 300, the analysis of the level of satisfying the traditional BoQ by utilizing the information that can be extracted from the BIM model showed that the level of information in the BIM model based on the number of items was $35 \%$, and the impossible information was $20.8 \%$. As a result of analyzing the ratio of construction costs, $22.68 \%$ of the BIM model's information was still available, and $10.31 \%$ of the information was impossible. Items that cannot be calculated will need to be incorporated into other items or improved by means of calculation using schematics. In addition to this level of information, it is necessary to improve the structure of traditional BoQ documents so that they can be utilized in conjunction with the BIM model. It was intended to present the framework of the information structure for the management of construction costs. This framework is constructed by adding element and space information that can be linked to the BIM model to the traditional BoQ, which enables the integrated operation of the BIMapplied construction cost management system as well as the traditional construction cost management system.
\end{abstract}

Keywords: BIM, Cost Management, BoQ, Cost Estimation, Quantity Takeoff, Quantity Database(QDB).

\section{Introduction}

As BIM application business expands, interest in Quantity takeoff using BIM and construction cost management is also increasing. However, there are many problems with the traditional construction cost management system itself, and the question remains whether the BIM-based construction cost management can improve work efficiency. Therefore, improving the efficiency of BIM should be accompanied by improvements to existing work processes as well as improvements to existing work outputs[1].

To this end, it is necessary to improve the composition system of Quantity takeoff or BoQ, which is related to construction costs, and to define the model of BIM and the interrelationships between them. Through this, it is necessary to analyze whether the current details according to the level of expression of the BIM model, i.e. level of development (LOD), are appropriate, and by analyzing the details that can be derived for each LOD level, it is judged that the current details system for BIM estimation can be improved.

The industry expects that the application of BIM will enable systematic construction cost management and maximize the efficiency of the work. However, a change in the traditional construction cost management system is necessary for systematic management of construction costs through BIM. In addition, various improvement measures at the working level should be developed for systematic management of construction costs.

In addition to this level of information, it is necessary to improve the structure of traditional BoQ documents so that they can be utilized in conjunction with the BIM model. It was intended to present the framework of the information structure for the management of construction costs. This framework is constructed by adding element and space information that can be linked to the BIM model to the traditional BoQ, which enables the integrated operation of the BIM-applied construction cost management system as well as the traditional construction cost management system.

\section{Literature Review}

Lee conducted a study to measure the completeness of BIM-based quantity takeoff results, taking issue with the lack of an accurate determination method for BIM-based estimates. To this end, BQI Matrix was presented from the BIM model to derive the factors of the BIM data that affect the quantity takeoff and to quantitatively measure the accuracy and completeness of the output based on the BIM data. The six pilot projects in the study wanted to verify their consistency and validity[2].

Lee wanted to present a BIM-based cost estimation method that can be applied to the domestic construction environment by classifying the BIM-based cost estimation method into different types of work. For this purpose, BIM modelling was performed based on definitions of BIM data linkage process and BIM model data

"Corresponding author: Seokheon Yun

Professor, Architectural Engineering Department, GyeongSang National University, JinjuSi

GyeongSangNamdo, 52828, Korea. Email address: gfyun@gnu.ac.kr 
construction to analyze the level and ratio of BIM model data linkage by type of work. However, since the analysis was based on the number of items only and based on the LOD level 400, it is deemed necessary to further study the possible linkage levels in the amount and whether the corresponding LOD levels are possible in all types of work[3].

To improve the work productivity of the BIM based cost estimation, Kim considered reducing working hours and productivity aspects of the BIM base cost estimation. The study sought to provide direction for the introduction of the initial BIM based cost estimation by defining the working conditions necessary for the efficient performance of the BIM base cost estimation work. However, the study was only focused on finishing work and was judged to have insufficient information on the level of detail in modeling and the accuracy of estimates for reduction in time and cost[4].

During the preparation of the BIM model, Bae wanted to investigate and analyze domestic and international LOD standards and application cases to prevent confusion caused by differences in the BIM model expression level. In addition, the analysis results highlighted the need to define LOD levels for the BIM model. However, it is deemed that further research is necessary because the information in the BIM will have a significant impact on the project's performance if problems in the design phase lead to confusion in the estimation and construction phases[5].

Roh wanted to define the level of representation of the model in order to apply the BIM model to the construction stage due to lack of consistency. To this end, the LOD level presented in domestic and international BIM guidelines was summarized, and the current status of BIM model expression level was analyzed through the survey, and the improvement plan was derived. However, even if there is a LOD standard, additional research is needed regarding the requirements of construction work because there was no clear definition of the LOD criteria for each worker and LOD not only represents the model but also includes the required tasks for each LOD level[6].

Song noted that although BIM is actively being introduced in construction projects through technological advances, the use of BIM in estimates or quantity calculations is very limited and there is no evaluation method. To explore this, the technical requirements for BIM to support the New Rule of Measurement (NRM) presented by the Royal Instrumentation of Chartered Surveyors (RICS) and the features and limitations of the BIM Estimation Tool (Tool) to apply to the UK Quantity Surveyor (QS)[7].

Ariani wanted to investigate how LOD was implemented in construction projects using BIM and the current status of LOD application. To this end, the definition and application purpose of each level of LOD were confirmed by theoretical consideration, and BIM Consultants were divided into public and private sectors and interviewed them. The results led to the conclusion that the definition of LOD was mostly similar, while the level of BIM model LOD expressed for each project varied[8].

Michał conducted a performance assessment of the BoQ in Poland as a problem with the error in quantity and the inconsistency in definition due to the absence of a unified principle and detailed guidance on the preparation of the statement. Performance measurement was performed by separating the traditional 2D-based BoQ, the digitalized BoQ and the BIM-based BoQ. As a result, the problems with traditional BoQ include printing, dimensional, quantity and unit price calculations, while digital and BIM-based BoQ have reduced errors and also reduced the time to prepare them. However, it was determined that further research is needed because digital or BIM-based statements should also include the time it takes to build the model and, in the case of BIM-based, how satisfied the framework of the traditional BoQ is also important[9].

Stephe et. al attempted to build a BIM model for the maintenance and management of the large architectural heritage of West Block through BIM. However, to address the difficulty of determining the LOD level of the BIM due to the size and complexity of the model, 75 Gothic arch parametric models existing in the case were developed to seek a solution to the problem[10].

Darren et al. conducted interviews and surveys on the quality issues of BIM models lacking consistency in BIM-based cost estimations to identify limiting factors for BIM-based cost estimations. As a result, it was determined that on average, the data required for quantity calculation, such as landscaping, formwork, rebars, other metals, temporary structures, and MEP, did not appear in the BIM model by 10 to $20 \%[11]$.

As a result of their consideration of BIM-based construction cost estimates and prior research literature related to LODs and specifications, they all wanted to analyze the limited factors for introducing BIM into construction projects and suggest ways to improve them. However, there is still a lack of research on the differences between the existing and BIM-based estimates and how to operate them at the practical level. Therefore, we would like to analyze the adequacy of the detailed items of the BoQ and the current BoQ based on the existing detailed statement, analyze the differences between the BIM-based construction cost estimate and the traditional BoQ, and come up with ways to integrate and operate them.

\section{LOD(Level of Development) and BIM based Cost Estimation}

\subsection{LOD for Quantity Takeoff}


It takes a lot of time and effort to satisfy the current details through the BIM model in a situation where the current details are limited to the engineering classification and the details are simply listed without interconnection. As a result, there is a lack of use of BIM-based quantity calculation function for detailed estimates in Korea[12].

LOD is used as 'Level of Detail' or 'Level of Development'. However, the LOD Specification published by BIM FORUM in the U.S. clearly distinguishes this concept. The LOD definitions in the LOD Specification of the BIM Forum are as follows: The LOD of 'Level of Detail' means how detailed the BIM model elements for each step are. In other words, the input concept focuses on how detailed the shape and property information of the BIM model is modeled in the BIM model or in the modeling, and how much detail it contains.

On the other hand, the 'Level of Development' LOD not only implies the detailed level of the BIM model, but also the reliability of the BIM model data when the information of the model is used and the meaning of the related tasks at each stage. In other words, it can be seen as an output concept to the extent that reliable BIM information is considered in the model as a higher concept of 'Level of Detail'. The following Table 1 is a comprehensive summary of the quantity takeoff related to the BIL of KBIMS and the LOD standards of AIA[13].

Table 1: LOD Criteria for Quantity Takeoff in KBIMS and AIA Standards

$\begin{array}{ccccc}\text { LOD 100 } & \text { LOD 200 } & \text { LOD300 } & \text { LOD400 } \\ \text { Phase } & \text { Conceptual } & \text { Schematic } & \text { Detailed } & \begin{array}{c}\text { Construction } \\ \text { \& Assembly }\end{array} \\ \text { Expression } & \text { Mass } & \begin{array}{c}\text { Existence of } \\ \text { main member }\end{array} & \begin{array}{c}\text { of all } \\ \text { structural and } \\ \text { construction } \\ \text { elements }\end{array} & \begin{array}{c}\text { Fabrication } \\ \text { and simulation }\end{array} \\ \text { Dimension } & \mathrm{X} & \mathrm{O} & \mathrm{O} & \mathrm{O} \\ \text { Material } & \mathrm{X} & \mathrm{O} & \mathrm{O} & \mathrm{O} \\ \text { Accessory } & \mathrm{X} & \mathrm{X} & \mathrm{X} & \mathrm{O}\end{array}$

Based on the information synthesis of AIA's LOD standards and KBIMS' BIL standards, the following Table 2 defines and summarizes the quantity takeoff information for LOD levels according to each type of work. LOD 100 is a mass form that is intended to identify the size and shape of the building, so it can be defined that there are no items to be quantified. LOD 200 is a model created by dividing into major sub-unit groups and is defined as a model that expresses approximate construction area calculation and openings for each type of construction. It is believed that there will be a detailed item to be calculated either directly or indirectly. LOD 300 is a modelling of all components and building elements, and is defined as most of the major elements of each type of construction being expressed. LOD 400 is defined as a construction detail model or assembly detail model that expresses the reinforcement of objects or building elements expressed at the LOD 300 level or all of the accessory materials, joints, joints, etc.

Table 2: Quantification range by Work Type from BIM model according to LOD

\begin{tabular}{|c|c|c|c|c|c|}
\hline & & $\begin{array}{l}\text { LOD 100 } \\
\text { (BIL 10) }\end{array}$ & $\begin{array}{l}\text { LOD 200 } \\
\text { (BIL 20) }\end{array}$ & $\begin{array}{c}\text { LOD } 300 \\
\text { (BIL30/40) }\end{array}$ & $\begin{array}{l}\text { LOD 400 } \\
\text { (BIL 50) }\end{array}$ \\
\hline \multirow{5}{*}{ General } & Phase & Conceptual & Schematic & Detailed & $\begin{array}{c}\text { Construction \& } \\
\text { Assembly }\end{array}$ \\
\hline & Expression & Mass & $\begin{array}{l}\text { Existence of } \\
\text { main member }\end{array}$ & $\begin{array}{c}\text { specification of all } \\
\text { structural and } \\
\text { construction } \\
\text { elements }\end{array}$ & $\begin{array}{l}\text { Fabrication and } \\
\text { simulation }\end{array}$ \\
\hline & Dimension & $\mathrm{X}$ & $\mathrm{O}$ & $\mathrm{O}$ & $\mathrm{O}$ \\
\hline & Material & $\mathrm{X}$ & $\mathrm{O}$ & $\mathrm{O}$ & $\mathrm{O}$ \\
\hline & Accessory & $X$ & $X$ & $\mathrm{X}$ & $\mathrm{O}$ \\
\hline \multirow{2}{*}{$\begin{array}{l}\text { Work } \\
\text { type }\end{array}$} & $\begin{array}{l}\text { Reinforced } \\
\text { Concrete }\end{array}$ & $X$ & $\begin{array}{l}\text { Approximate } \\
\text { Concrete }\end{array}$ & Concrete Quantity & Concrete, Rebar \\
\hline & Masonry & $X$ & $\begin{array}{c}\text { Approximate } \\
\text { Area }\end{array}$ & $\begin{array}{l}\text { Brick, Block, } \\
\text { Lintel }\end{array}$ & $\begin{array}{l}\text { Stud, Reinforcing, } \\
\text { Mesh, Anchor }\end{array}$ \\
\hline
\end{tabular}




\begin{tabular}{|c|c|c|c|c|}
\hline Stone & $X$ & $\begin{array}{l}\text { Approximate } \\
\text { Area }\end{array}$ & Stone & Stud \\
\hline Tile & $X$ & $\begin{array}{l}\text { Approximate } \\
\text { Area }\end{array}$ & Tile & Stud \\
\hline $\begin{array}{l}\text { Carpentry \& } \\
\text { Finishing }\end{array}$ & $\mathrm{X}$ & \multirow{3}{*}{$\begin{array}{l}\text { Approximate } \\
\text { Area }\end{array}$} & $\begin{array}{l}\text { Exterior, Interior, } \\
\text { Insulation }\end{array}$ & Furniture \\
\hline Waterproof & $\mathrm{X}$ & & All Layer & $\begin{array}{c}\text { Joint } \\
\text { Caulking }\end{array}$ \\
\hline $\begin{array}{l}\text { Roof \& } \\
\text { Drain }\end{array}$ & $\mathrm{X}$ & & Gutter & Accessory \\
\hline Metal & $\mathrm{X}$ & & $\begin{array}{l}\text { Molding, Handrail } \\
\text { Ladder, Ceiling bar } \\
\text { Curtain box }\end{array}$ & $\begin{array}{l}\text { Reinforcing, Parapet } \\
\text { ring, Handle }\end{array}$ \\
\hline Plaster & $\mathrm{X}$ & $\begin{array}{l}\text { Approximate } \\
\text { Area }\end{array}$ & Mortar & Joint \\
\hline $\begin{array}{l}\text { Window \& } \\
\text { Glass }\end{array}$ & $\mathrm{X}$ & Opening & Frame, Glass & Accessory \\
\hline Painting & $\mathrm{X}$ & $\begin{array}{l}\text { Approximate } \\
\text { Area }\end{array}$ & All Layer & \\
\hline
\end{tabular}

\subsection{Analysis of Quantity takeoff Level from BIM Model}

In order to utilize the BIM model for quantity takeoff or cost estimation, it is necessary to determine to what extent the information provided by the model can provide the information needed for quantity takeoff or cost estimation. The more detailed the BIM model is produced, the more information it can provide for quantity takeoff or cost estimation. However, it is not possible to create models in infinite detail just for quantity takeoff or cost estimation.

Generally, the detailed level of the model or the stage of the model's production is defined as LOD. The step of quantity takeoff using the BIM model is a completion of the detail design, and the model is often created at the LOD level 300. Although there may be differences between projects, this study wanted to analyze the level of quantity required for quantity takeoff in the BIM model based on LOD 300. In addition, depending on the information provided, it can be used directly for Quantity takeoff, or it can be used by adjusting the figures provided, applying formulas, or providing no information needed for Quantity takeoff. In this study, this factor was divided into A through $\mathrm{D}$ as follows:

A: Quantification is Available from BIM Model Directly

B: Quantification Available with BIM Model and Other Design Document

C: Additional Calculation is Required for Quantification from BIM Model

D: Quantification from BIM Model is Unavailable

In this study, Table 3 shows the results of the analysis divided into levels A and D defined above for the general office buildings where quantity calculation and details were prepared. There were 128 items (A) available for Quantity takeoff, about 975,942,861 Won, 110 items (B) to be used with other design information, and about 1,350,035,762Won. There were 51 items (C) that should be used by calculating the information in the BIM model as an additional formula, and the amount was approximately 1,532,850,586Won. In addition, 76 items and approximately 443,599,482 Won were not available in the BIM model for the required information for cost estimation.

Table 3: Quantification from BIM with LOD 300

\begin{tabular}{ccccc}
\hline & A & B & C & D \\
\hline Items(EA) & 128 & 110 & 51 & 76 \\
Cost(KW) & $975,942,861$ & $1,350,035,762$ & $1,532,850,586$ & $443,599,482$ \\
\hline
\end{tabular}

The above results are shown in Figure 1. Items (A) that could directly use the information provided by the model for quantity takeoff were approximately $35 \%$, and the amount was $22.68 \%$, and items that should be used with other design information (B) were $30.14 \%$, and the amount was approximately $31.38 \%$. The items (C) that should be used by calculating the information in the BIM model in an additional formula were approximately $13.97 \%$ and by amount were approximately $35.63 \%$. In addition, items that could not be provided by the BIM 
model were approximately $20.82 \%$ and $10.31 \%$ in amount.

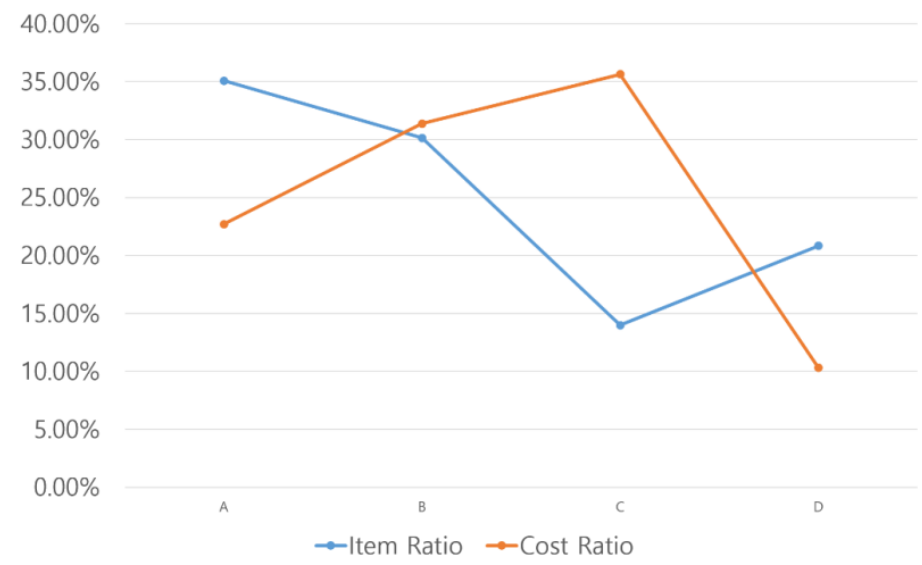

Figure 1. Quantification Available Level

\section{Integration of traditional quantity takeoff with BIM using QDB}

Cost estimation systems using BIM have recently been developed, but they are implemented around the function of calculating quantities through the BIM model, which has limitations in how they are linked to traditional cost estimation systems. In addition, since the BIM model alone cannot secure the entire quantity takeoff data for cost estimation, integration with the traditional cost estimation method is necessary.

In order to implement this, it is deemed necessary to have a quantity takeoff and cost estimation framework that can support both 2D and BIM based cost estimates. In this study, we want to implement this integrated quantitative data framework in the form of QDB (Quantity Database).

Figure 2 presents the integrated operation of the existing quantity takeoff and cost estimation process through QDB and the quantity takeoff and cost estimate through BIM. Using this framework, traditional quantity takeoff document and BoQ can also be operated as they are, and if necessary, the quantity and construction cost by elements and space units can be analyzed or verified.



Figure 2. Integrated quantity/construction cost information framework based on QDB

To increase the utilization of these frameworks, they should be implemented in a similar format to the traditional BoQ or Quantity Takeoff configuration. In the traditional BoQ and Quantity Takeoff configurations, what is lacking in integrating with the BIM model is element and space related information.

BIM uses the method of designing the final building through the combination of objects, and to support the quantity takeoff information and BoQ based on these systems, the site and space related information which is the composition of these buildings are needed. Here, in order to use this information in conjunction with 
construction process or other purposes, it is necessary to standardize the classification system of the space and element. Figure3 shows a QDB template created by adding space and element information to the existing BoQ document format in Korea.

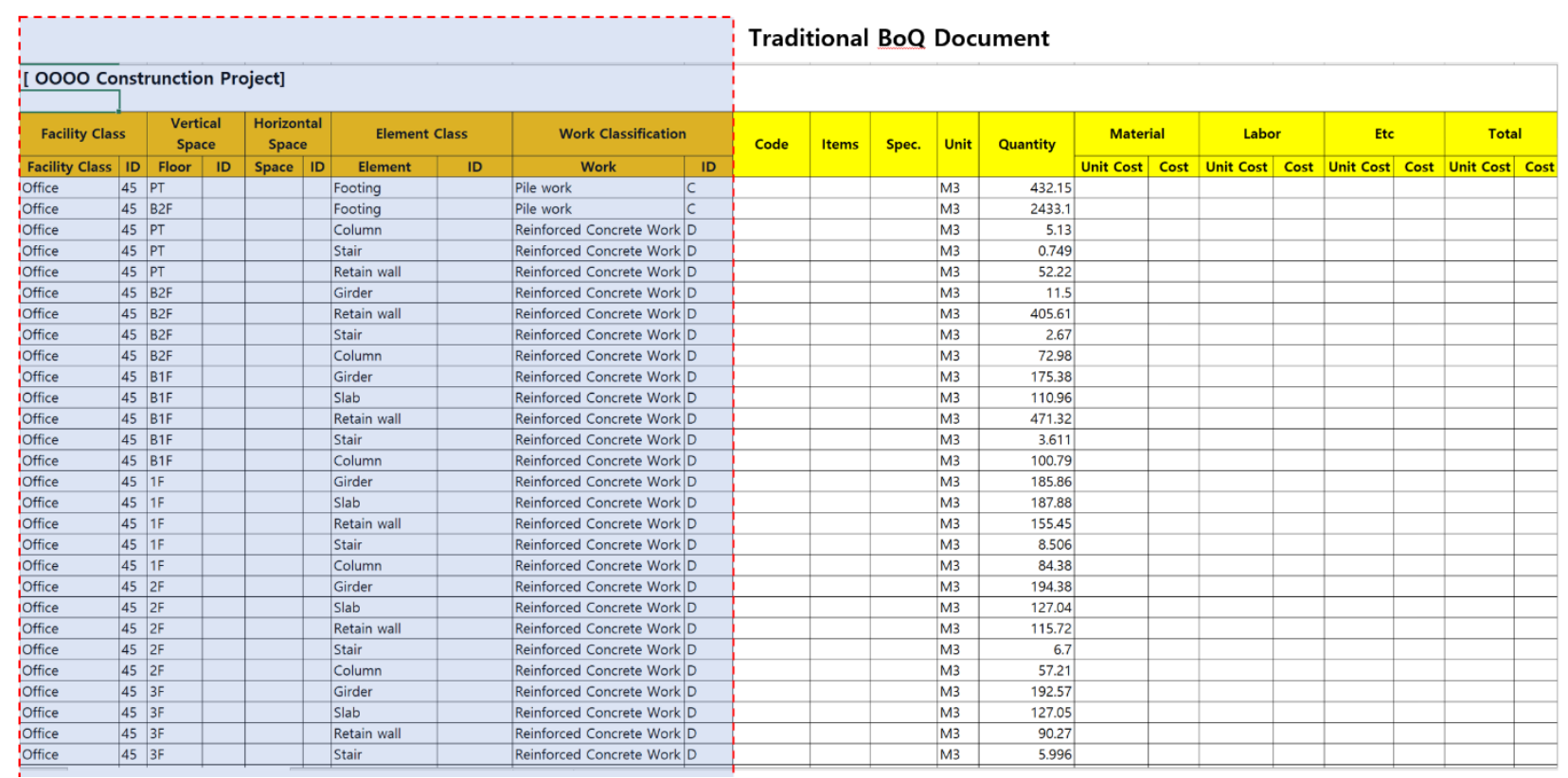

Figure 3. BoQ template with QDB suggested in this study

In the QDB Template above, the right part is the traditional BoQ document format, and the newly added left part is the information about the space and element of the item. The structure of the building is calculated in element units with Quantity takeoff and BOQ. This is because the construction itself of the structure consists of floors and each part of the structure. Figure 4 illustrates an example of a structural model for calculating the quantity and construction cost of a structure construction in the BIM model. On the other hand, in the case of finishing work, the quantity and construction cost of finishing work are calculated in space units, not in parts.

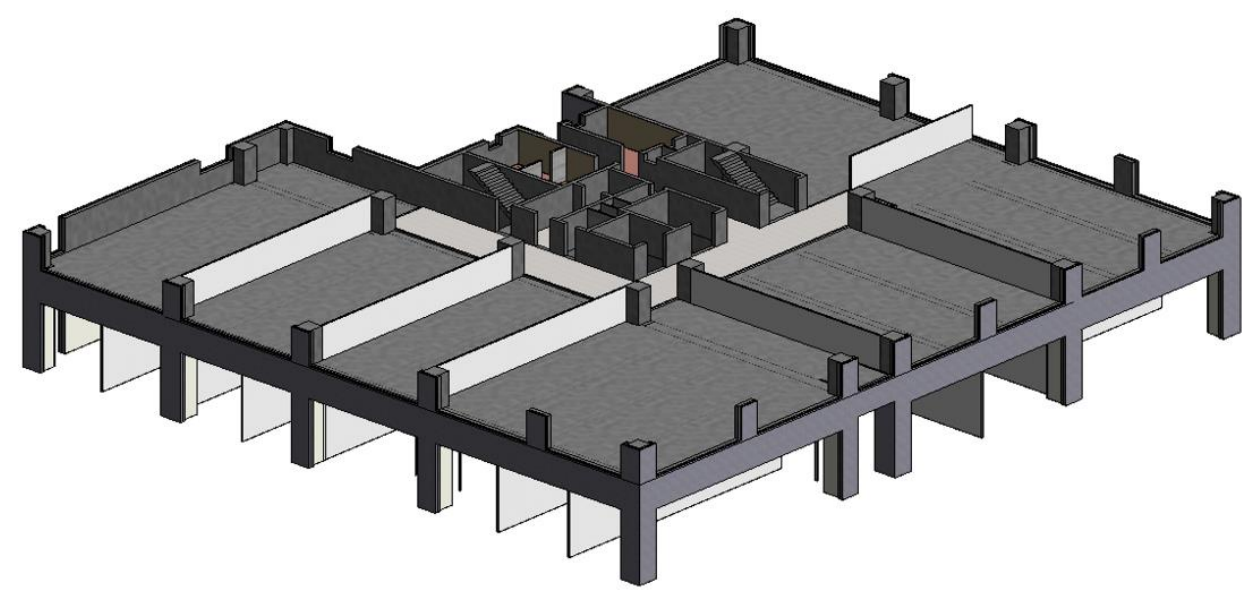

Figure 4. BIM Structure Model for Quantification

\section{Conclusion}

Based on LOD 300, the analysis of the level of satisfying the traditional BoQ by utilizing the information that can be extracted from the BIM model showed that the level of information in the BIM model based on the number of items was $35 \%$, and the impossible information was $20.8 \%$. As a result of analyzing the ratio of construction costs, $22.68 \%$ of the BIM model's information was still available, and $10.31 \%$ of the information was impossible. Items that cannot be calculated will need to be incorporated into other items or improved by means of calculation using schematics. In addition to this level of information, it is necessary to improve the structure of traditional BoQ documents so that they can be utilized in conjunction with the BIM model. It was intended to present the framework of the information structure for the management of construction costs. This 
framework is constructed by adding element and space information that can be linked to the BIM model to the traditional BoQ, which enables the integrated operation of the BIM-applied construction cost management system as well as the traditional construction cost management system.

\section{Acknowledgment}

This work was supported by the National Research Foundation of Korea(NRF) grant funded by the Korea government (NRF-2019R1A2C1005833).

\section{References}

1. Rafael S, Chales E, Lee G, Paul T. BIM Handbook : A Guide to Building Information Modeling for Owners, Designers, Engineers, Contractors, and Facility Managers, 3rd Edition. New Jersey: John Wiley \& Sons, Inc.; 2018. p. 8.

2. Lee CH, Kim SA, Chin SY. An Index for Measuring the Degree of Completeness of BIM-based Quantity Take-Off. Journal of Korea Institute of Construction Engineering and Management. 2011;12(6):79-92.

3. Lee CH, Kim JM, Choi CH, Song SH. BIM-based cost estimation by integration with BIM model data and cost information - Case Study on Economy Evaluation of Apartment in Sejong Special SelfGoverning city. Journal of Korean Institute of BIM. 2017;7(3): 11-20.

4. Kim SA, Park K, Song BS, Choi CH, Chin SY. A Study on Setting Up Work Conditions for Improving Productivity of BIM-based Cost Estimation. Journal of Korea Institute of Construction Engineering and Management. 2016;17(1): 56-65.

5. Bae KJ, Chun HJ. A Case Study on LOD(Level of Development) studies for BIM Model. Journal of Society of Design Convergence. 2011;10(5): 31-43.

6. Noh HR, Kim JY, Lee DW, Yun SH. A Study for the Optimal Expression Level Definition of BIM Model in Construction Phase. Journal of Society for Computational Design and Engineering. 2016;21(4): 378-388.

7. Song W, Gerard W, Kanchana G, Siaw WJ. A Technical Review of BIM Based Cost Estimating in UK Quantity Surveying Practice, Standards, and Tools. Journal of Information Technology in Construction.2014;19: 534-562.

8. Aryani AL, Juliana B, Suzila M, Mohamad SF. Building Information Modeling(BIM) : Exploring Level of Development(LOD) in Construction Project. Applied Mechanics and Materials. 2015;773744:933-937.

9. Michał J, Agnieszka L, Krzysztof Z. Selected Issues of Bills of Quantities in Construction Work in Poland, Journal of Science of the Military Academy of Land Forces. 2017;49(1):189-200.

10. Stephen F, Jesse R. Establishing an Appropriate Level of Detail(LOD) for a Building Information Model(BIM), ISPRS Annals of the Photogrammetry, Remote Sensing and Spatial Information Sciences. 2014;2(5):123-130.

11. Darren JD. Mark T. Quantity Take-Off Using Building Information Modeling(BIM), and Its Limiting Factors, Procedia Engineering. 2017;196:1098-1105.

12. Lee JH. A Case Study on the Detailed Estimate Using BIM [master's thesis]. Seoul: ChungAng University;2010.

13. Choi HJ. LOD Criteria Analysis and Improvement of Quantity Take-Off and BOQ System for Improving Efficiency of the BIM-based Cost Estimation [master's thesis]. JinJu: GyeongSang National University;2020. 